Saudi Journal of Oral and Dental Research

Abbreviated Key Title: Saudi J Oral Dent Res ISSN 2518-1300 (Print) |ISSN 2518-1297 (Online) Scholars Middle East Publishers, Dubai, United Arab Emirates Journal homepage: http://scholarsmepub.com/sjodr/

\title{
Effect of Thermo-mechanical Cyclic Stresses on Flexural Strength of Two Aesthetic Restoratives with Modified Filler Systems
}

\author{
Hala A. Bahgat, BDS, MSc, $\mathrm{PhD}^{1}$, Alaa A. Alshaia ${ }^{2}$, Alaa A. Abdullah ${ }^{2 *}$, AlAnoud H. Aldubayan ${ }^{2}$, Sarah I. Al-Urifan ${ }^{2}$, \\ Neveen M. Ayad, BDS, MSc, $\mathrm{PhD}^{3}$ \\ ${ }^{1}$ Professor, Restorative Dental Sciences Department, College of Dentistry, Imam Abdulrahman Bin Faisal University, Dammam, Kingdom of Saudi \\ Arabia \\ ${ }^{2}$ Dental Intern, College of Dentistry, Imam Abdulrahman Bin Faisal University, Dammam, Kingdom of Saudi Arabia \\ ${ }^{3}$ Associate Professor, Restorative Dental Sciences Department, College of Dentistry, Imam Abdulrahman Bin Faisal University, Dammam, Kingdom of \\ Saudi Arabia
}

DOI: $10.36348 /$ SJODR.2019.v04i10.011 $\quad$ | Received: 21.10.2019| Accepted: 28.10.2019| Published: 30.10 .2019

*Corresponding author: Dr. Alaa A. Abdullah

\section{Abstract}

Background: Numerous restorations have been used in dentistry to substitute the lost natural tooth structure. In attempts to improve the mechanical properties of glass ionomer, a nano-zirconia reinforced glass ionomer was introduced. The aim of the study was to compare the impact of cyclic stresses on flexural strength of two aesthetics restorative materials. Materials and methods: A nano-hybrid composite resin and a nano-zirconia reinforced glass ionomer were used in this study. A total of 80 specimens, 40 for each restorative were fabricated. In each group, 10 specimens were assigned for each aging condition as following; control, thermo-cyclic stresses, mechanical-cyclic stresses and combined thermomechanical cyclic stresses. Then the specimens were submitted to 3-point loading test using the Universal Testing Machine. Results: In all test conditions, nano-hybrid composite resin showed statistically significant higher mean flexural strength than nano-zirconia reinforced glass ionomer (61.1 MPa SD $\pm 17.3,24.2 \mathrm{MPa} \mathrm{SD} \pm 9.9 \mathrm{P}$-value $<0.001)$. The control condition showed the highest statistically significant mean flexural strength (59.4 MPa SD \pm 26.8, Pvalue $<0.001)$, while the combined condition showed the lowest statistically significant mean of flexural strength $(29.7$ $\mathrm{MPa}, \mathrm{SD} \pm 15.9$, P-value <0.001). Conclusions: Nano-hybrid composite showed superior performance than zirconia reinforced glass ionomer when subjected to cyclic stresses; either thermal, mechanical or combined.

Keywords: Composite resin, dental material, glass ionomer, mechanical properties, nanofillers, dental restorations.

Copyright @ 2019: This is an open-access article distributed under the terms of the Creative Commons Attribution license which permits unrestricted use, distribution, and reproduction in any medium for non-commercial use (NonCommercial, or CC-BY-NC) provided the original author and source are credited.

\section{INTRODUCTION}

The ultimate target of the restorative materials is to substitute the lost natural tooth structure biologically, physically, mechanically, and functionally. Such replacement is compromised by the complex stresses generated from dynamic thermal and masticatory forces in the oral cavity resulting in deformation, distortion or even fracture of the restoration by time. [1] Nowadays composite resin and glass ionomer symbolize the most popular direct restorative materials, because each separately fulfils a wide range of the ideal requirements. However, both materials lend themselves for progressive developments to improve their shortcomings [2-4].

Nanotechnology, the science of matter at billionth of meter in size, is one of the recent contributors in their advancements that have revolutionized the filler system incorporated in composite resin and glass ionomer [5].

In the current composite resins, high filler loading is attained by blending micro and nano-sized particles, thus improving the mechanical strength, minimizing polymerization shrinkage and providing better aesthetic characteristics [6, 7]. All these improvements are guaranteed by the complete spherical shaped filler particles that allow the maximum packing density as in "Ceram X universal". The latter gives a new dimension to the composite restorations by its Sphere-Tec, the latest technology in the filler system [8, 9].

On the other hand, the incorporation of nanosized zirconia fillers, renowned by its reinforcing behaviour, to the conventional glass ionomer powder has helped to overcome its low flexural strength and 
fracture toughness; enhance material translucency; and finally provide superior handling [10-12]. This new member "Zirconomer Improved" to the glass ionomer family is also claimed by the manufacturer as new improved eco-friendly white amalgam, because it combines the benefits of both dental amalgam and conventional glass ionomer [13].

As both restorative materials are featured by their advanced filler systems, their mechanical sustainability in the aggressive oral environment will be one of the fundamental concerns regarding their performance.

Flexural strength is a significant mechanical property to evaluate the strength of brittle materials, as the investigated restoratives. Flexural strength, also known as transverse strength or modulus of rapture, is one the important mechanical properties that determines resistance to failure under complex stresses. Such condition reflects the nature of the oral stresses [1].

Laboratory mock-ups of clinical service are often conducted during testing of the physico- mechanical properties of the restoratives to elucidate the aging effect of thermal, mechanical and chemical fluctuations besides the sorption and desorption characteristics on their performance, because clinical trials are usually costly and time consuming $[14,15]$.

Therefore, the aim of this research was to explore the impact of the various stresses: thermal, mechanical or combined on the flexural strength of the Ceram X universal and Zirconomer Improved. The subsequent null hypotheses were tested: 1) No difference exists in the flexural strength values of the nano-hybrid composite resin and the zirconia reinforced glass ionomer. 2) The different aging conditions do not affect the flexural strength of the nano-hybrid composite resin and the zirconia reinforced glass ionomer.

\section{MATERIALS AND METHODS Materials}

Two nano-restoratives were designated for this research. (Table1)

Table-1: Detailed description of the designated nano-restoratives.

\begin{tabular}{|c|c|c|c|c|c|}
\hline $\begin{array}{l}\text { Restorative } \\
\text { material }\end{array}$ & Code & Type & Composition & Manufacturer & Lot number \\
\hline Ceram X & $\mathrm{CX}$ & $\begin{array}{l}\text { Nano-hybrid } \\
\text { composite resin }\end{array}$ & $\begin{array}{l}\text { Filler type and particle size: } \\
\text { Blend of pre-polymerized Sphere TECTM fillers } \\
\text { (Methacrylate functionalised silicon dioxide nano } \\
\text { filler), non-agglomerated barium glass }(0.6 \mu \mathrm{m}) \\
\text { and ytterbium fluoride }(0.6 \mu \mathrm{m}) \\
\text { Filler loading: } \\
77-79 \text { by weight } \% \\
\text { (59-61\% by volume) } \\
\text { Matrix: } \\
\text { Methacrylate modified poly-siloxane } \\
\text { Di-methacrylate resin }\end{array}$ & $\begin{array}{l}\text { Dentsply, DeTrey } \\
\text { GmbH, Konstanz, } \\
\text { Germany }\end{array}$ & 1609000376 \\
\hline $\begin{array}{l}\text { Zirconomer } \\
\text { Improved }\end{array}$ & ZI & $\begin{array}{l}\text { Zirconia } \\
\text { reinforced glass } \\
\text { ionomer cement }\end{array}$ & $\begin{array}{l}\text { Powder: } \\
\text { Fluoro-aluminosilicate glass, Zirconium oxide, } \\
\text { pigments and others } \\
\text { Liquid: } \\
\text { Polyacrylic acid solution and Tartaric acid }\end{array}$ & $\begin{array}{l}\text { Shofu Inc. Kyoto, } \\
\text { Japan }\end{array}$ & 12150285 \\
\hline
\end{tabular}

\section{Methods \\ Preparation of nano-hybrid composite resin $(\mathrm{CX})$ specimens}

In accordance to ISO 4049 specifications [16], forty bar shaped flexural strength specimens were prepared at room temperature of $23 \pm 1{ }^{\circ} \mathrm{C}$ and in a relative humidity of $50 \pm 10 \%$ in customized split Teflon mold, measuring $2 \mathrm{~mm}$ height $\times 2 \mathrm{~mm}$ width $\times 25 \mathrm{~mm}$ length. The composite resin was injected directly from its respective syringe into the mold which was squeezed between two plastic bands and two microscopic slides to express the excess and ensure proper surface finish. The specimens were then polymerized from upper and lower sides through the plastic bands, to avoid the occurrence of oxygen-inhibited layer on the surface of the specimen, by means of a light emitting diode light source (Elipar free light, 3M, ESPEAG, Dental Products, St. Paul, Seefeld Germany) with $8 \mathrm{~mm}$ curing tip in five overlapping exposures, $20 \mathrm{~s}$ duration each, at an intensity of $600 \mathrm{~m} \mathrm{~W} / \mathrm{cm}^{2}$; verified between specimens using a radiometer. The overlapping irradiations are required, as the exit window of the light-cure unit is smaller than $25 \mathrm{~mm}$. After irradiation, the specimens were removed from the mold. The excess flash was removed by abrading with P150 abrasive paper without touching the upper and lower surfaces. Then the specimens were immediately stored in distilled water at $37^{\circ} \mathrm{C}$ for $24 \mathrm{~h}$ before testing. 
Hala A. Bahgat et al; Saudi J Oral Dent Res, Oct 2019; 4(10): 751-759

Preparation of nano-zirconia reinforced glass ionomer (ZI) specimens

In accordance to ISO 4049 specifications [16], forty bar shaped flexural strength specimens were prepared at room temperature of $23 \pm 2{ }^{\circ} \mathrm{C}$ and in a relative humidity of $50 \pm 10 \%$ in customized split Teflon mold, measuring $2 \mathrm{~mm}$ height $\times 2 \mathrm{~mm}$ width $\times$ $25 \mathrm{~mm}$ length. The nano-zirconia reinforced glass ionomer is a hand-mixed version. Therefore, mixing the powder/ liquid ratio according to manufacturer's instruction was done with plastic spatula on impermeable mixing pad; then the thick putty-like mix was immediately condensed in excess into the mold which is squeezed between two plastic bands and two microscopic slides to express the excess and ensure smooth surface finish. The set specimens were then removed from the mold. The excess flash was abraded with P150 abrasive paper without touching the upper and lower surfaces. Finally, the specimens were painted with two coats of Cocoa Butter for protection against desiccation. Then the specimens were immediately stored in distilled water at $37^{\circ} \mathrm{C}$ for $24 \mathrm{~h}$ before testing.

\section{Grouping of specimens}

The specimens were allotted to one of the following groups:

\section{Group I: Control group $(\mathrm{C})=$ Baseline}

Ten specimens of each investigated restorative material, stored in distilled water at $37^{\circ} \mathrm{C}$ for $24 \mathrm{~h}$, were blotted dry with filter paper and then the 3-point loading test was conducted to measure the flexural strength.

\section{Group II: Thermo-cyclic group (TC)}

Ten specimens of each investigated restorative material in a mesh bag were subjected to10,000 thermal cycles between two water chambers representing the maximum and minimum temperatures in the oral cavity: $\quad 55 \pm 2{ }^{\circ} \mathrm{C}$ and $5 \pm 2{ }^{\circ} \mathrm{C}$. (Thermo-scientific Precision Water Baths Model 2854; Clarkson Laboratory \& Supply Inc., Chula Vista, CA). The immersion period in each water chamber was $30 \mathrm{~s}$ and the travelling time between two chambers was $15 \mathrm{~s}$. [15]

Once this aging process was complete, the specimens were blotted dry with filter paper, and then the 3-point loading test was conducted to measure the flexural strength.

\section{Group III: Mechanical cyclic group (MC)}

Ten specimens of each investigated restorative material were subjected to mechanical cyclic loading in a chewing simulator machine (Multi-functional Chewing Simulator CS-4.2; SD Mechatronik, Feldkirchen-Westerham, Germany). In this study, an intermittent axial chewing force of $68.6 \mathrm{~N}$ was delivered to the specimen 10,000 times with a frequency of $1.2 \mathrm{~Hz}$, because clinically the mean physiological chewing force is expected to range from
49 to $150 \mathrm{~N}$ with a frequency range of 1.2 to $1.6 \mathrm{~Hz}$ [17, $18]$. Once this aging process was complete, the 3-point loading test was conducted to measure the flexural strength.

\section{Group IV: Mechanical and thermal cyclic group (MTC)}

Ten specimens of each investigated restorative material were subjected first to mechanical cycling then thermal cycling as discussed before. Once this aging process was complete, the 3-point loading test was conducted to measure the flexural strength,

\section{The 3-point loading test}

Following each aging test condition, the specimen dimensions (Length, width, and height) were verified at their centres to an accuracy of $0.01 \mathrm{~mm}$ using a digital micrometre. Afterwards, each specimen was positioned in a 3-point loading test set up on 2 parallel supports $20 \mathrm{~mm}$ apart from each other, and then loaded until fracture using a universal testing machine with a $5 \mathrm{KN}$ load cell at a crosshead speed of 1.0 $\mathrm{mm} / \mathrm{min}$. The load-to-failure of each specimen was recorded in Newton. The flexural strength in MPa was automatically calculated using the computerized programmed based on the formula mentioned below. Flexural strength $(\mathrm{FS})=3 \mathrm{Fl} / 2 \mathrm{wh}^{2}$

Where:

F - Load exerted at failure in Newton.

1 - Span between the parallel supports in milli-meter (20.0 mm).

$\mathrm{w}$ - Specimen width in milli-meter.

$\mathrm{h}$ - Specimen height in milli-meter.

\section{STATISTICAL ANALYSIS}

Numerical data were explored for normality by checking the distribution of data and using tests of normality (Kolmogorov-Smirnov and Shapiro-Wilk tests). Data showed normal (parametric) distribution. Data were presented as mean, standard deviation (SD) and $95 \%$ confidence interval $(95 \% \mathrm{CI})$ for the mean values. Two-way Analysis of Variance (ANOVA) was used to study the effect of material, condition and their interaction on mean flexural strength concentration. Bonferroni's post-hoc test was used for pair-wise comparisons when ANOVA test is significant. The significance level was set at $\mathrm{P} \leq 0.05$. Statistical analysis was performed with IBM $®$ SPSS $®$ Statistics Version 20 for corrections $[19,20]$.

\section{RESULTS}

\section{Two-way ANOVA results}

The results showed in (Table 2) that the restorative type had a statistically significant effect on the mean flexural strength $(P$-value $<0.001$, Effect size $=$ $0.851)$ regardless of the effect of aging condition. The latter had also a statistically significant effect on the mean flexural strength $(P$-value $<0.001$, Effect size $=$ 
Hala A. Bahgat et al; Saudi J Oral Dent Res, Oct 2019; 4(10): 751-759

0.656) regardless of the effect of the restorative type. The interaction between the two variables had a statistically significant effect on the mean flexural strength $(P$-value $<0.001$, Effect size $=0.252)$. Since the interaction between the variables is statistically significant, so the variables were dependent upon each other.

\section{Effect of different interactions \\ Comparison between restoratives within each aging condition}

CX showed statistically significantly higher mean flexural strength than $\mathrm{ZI}$ in all test regimens: control condition ( $P$-value $<0.001$, Effect size $=0.723$ ), thermo-cycled condition; $(P$-value $<0.001$, Effect size $=$ $0.461)$, mechanical-cycled condition: $(P$-value $<0.001$, Effect size $=0.632$ ), and finally the combined thermoand mechanical-cycled condition: ( $P$-value $<0.001$, Effect size $=0.461)$. (Table 2, Figure1)

\section{Comparison between different aging conditions} within each material

Pair-wise comparisons between the aging conditions of $\mathrm{CX}$ revealed that control showed the statistically significantly highest mean flexural strength. There was no statistically significant difference between thermo-cycled and mechanical-cycled specimens; both showed lower mean flexural strength values. The statistically significantly lowest mean flexural strength was observed with the combination of both thermo- and mechanical-cycled condition. (Table 2, Figure1).

Pair-wise comparisons between the aging conditions of ZI revealed that control showed the statistically significantly highest mean flexural strength. There was no statistically significant difference between thermo-cycled and mechanical-cycled specimens; both showed lower mean flexural strength values. The statistically lowest mean flexural strength was observed with the combination of both thermo- and mechanicalcycled condition. Combination condition showed statistically significantly lower mean flexural strength than control and thermo-cycled condition and nonstatistically significant difference from mechanicalcycled condition. (Table 2, Figure1)

Table-2: The mean flexural strength (MPa), standard deviation (SD), 95\% confidence interval (95\% CI) values and results of two-way ANOVA test for comparison between flexural strength of the different interactions

\begin{tabular}{|c|c|c|c|c|c|c|}
\hline Condition & Ceram X & $\begin{array}{c}\text { Zirconomer } \\
\text { Improved }\end{array}$ & $\begin{array}{c}\text { Partial Eta } \\
\text { Squared } \\
\text { (Effect size })\end{array}$ & $\begin{array}{c}\text { P-value(Between } \\
\text { materials) }\end{array}$ \\
\hline & $\begin{array}{c}\text { Mean } \\
\text { FS (MPa) } \\
(\mathrm{SD})\end{array}$ & $95 \% \mathrm{CI}$ & $\begin{array}{c}\text { Mean } \\
\text { FS (MPa) } \\
(\mathrm{SD})\end{array}$ & $95 \% \mathrm{CI}$ & & \\
\hline Control & $84.3(8.0)^{\mathrm{A}}$ & $79.2-89.4$ & $34.4(8.5)^{\mathrm{A}}$ & $29.3-39.5$ & 0.723 & $<0.001^{*}$ \\
\hline Thermo-cycled & $54.7(8.1)^{\mathrm{B}}$ & $49.6-59.9$ & $26.2(9.5)^{\mathrm{B}}$ & $21.1-31.4$ & 0.461 & $<0.001^{*}$ \\
\hline $\begin{array}{c}\text { Mechanical } \\
\text { cycled }\end{array}$ & $61.2(11.8)^{\mathrm{B}}$ & $56.1-66.3$ & $20.8(4.3)^{\mathrm{BC}}$ & $15.7-25.9$ & 0.632 & $<0.001^{*}$ \\
\hline Both & $44.0(7.4)^{\mathrm{C}}$ & $38.9-49.1$ & $15.4(4.9)^{\mathrm{C}}$ & $10.3-20.6$ & 0.461 & $<0.001^{*}$ \\
\hline $\begin{array}{c}\text { Partial Eta } \\
\text { Squared } \\
\text { (Effect size) }\end{array}$ & 0.647 & & 0.293 & & & \\
\hline $\begin{array}{c}P \text {-value } \text { (Between } \\
\text { conditions) }\end{array}$ & $<0.001^{*}$ & & & & & \\
\hline
\end{tabular}

*: Significant at $P \leq 0.05$, Different superscripts in the same column are statistically significantly different

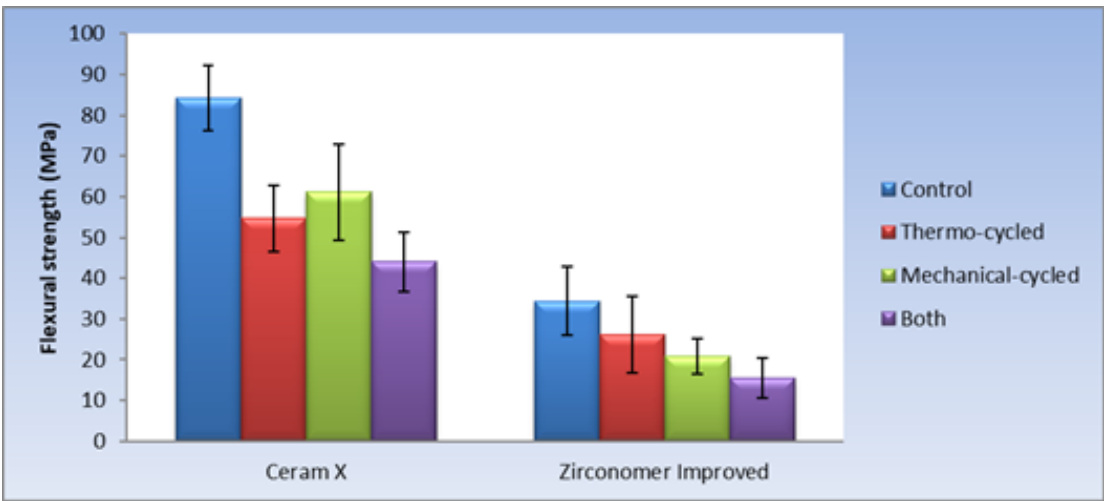

Fig-1: Bar chart representing mean flexural strength (MPa) and standard deviation values for flexural strength of the different interactions 


\section{DISCUSSION}

CX is described as a nano-hybrid composite comprising organically modified ceramic nanoparticles of poly-siloxane backbone. The latter can be best designated as inorganic - organic hybrid particles where the inorganic siloxane section gives strength and the organic methacrylic share grants the particles polymerization with the polymeric matrix [6-9].

On the other hand, ZI is developed by the incorporation of novel nano-sized zirconia fillers into conventional glass ionomer to enhance material's strength, handling and translucency with the aim of displaying durability similar to amalgam [21].

When reviewing the reasons for replacement of dental restorations, their bulk fracture during service seems to be among the most relevant causes following the recurrent caries [22].

Therefore, understanding of the mechanical behaviour of these two nano-restoratives in test conditions imitating the destructive oral environment is valuable in assessing their functional survival rates [23]. This will lead certainly to more proper selection of the restorative to the appropriate application.

As a rule of thumb, stronger materials allow for more equal stress distributions, and better deformation tolerance, thus reducing the risk of failure and increasing the long-term clinical service. The threepoint loading test for flexure strength has been chosen by the International Standards Organization as an efficient indicator for a resin-based filling's sustainability under complex masticatory stresses [24]. Also, lately, the three-point loading test for flexure strength has been also strongly recommended as a substitutive for compressive fracture strength test described in the International Organisation for Standardisation (ISO 9917-1: 2007) [25], as the lone distinctive performance testing of glass ionomer restoratives [26-28].

The flexural strength is described as the ultimate stress that a material can bear before failure when subjected to bending. It is considered a simultaneous intermingling of compressive stresses at the upper face of the specimen, tensile stresses at its lower face, and shear stresses parallel to the applied loading. Therefore, it is the most proper representative of the strength as a material could only fail by either separation or slipping of atomic planes (i.e. tensile or shear failures respectively) [1].

Moreover, ISO 4049 categorises dental resinous restoratives into two types: Type I comprises filling materials appropriate for restorations of stress bearing surfaces, and Type II includes filling materials for other indications. Thus, a minimum of $80 \mathrm{MPa}$ is required for flexural strength for Type I and $50 \mathrm{MPa}$ for Type II [16, 29].
Regarding the mean values of flexural strength for both evaluated nano-restoratives, the first null hypothesis of the study was rejected, where CX showed higher flexural strength than ZI throughout the experimental study in all tested groups. CX in the control group was in the range of the threshold value set by the ISO standard for flexural strength in posterior restorations, while ZI displayed unfortunately lower value than the suggested one. Taking this into the account, CX could be used safely for stress bearing restorations, while $\mathrm{ZX}$ employment in paediatric or geriatric restorations would be more appropriate, for the quite low masticatory stresses applied to these restorations and their limited service period in the oral cavity.

The difference in the mechanical behaviour of both restoratives could be directly related to the integrity of their structural architecture. This corroborates to the findings in previous studies Geirsson et al. 2004 and Rodrigues et al. 2015. [30, 31]. The inclusion of air voids in the final set structure is considered structural flaws acting as a source of stress concentration increasing both the heterogeneity and naturally the brittleness of the restorative material, and finally, rendering the material more prone to fracture under flexure [1].

$\mathrm{CX}$, as nanohybrid composite set by addition polymerization at room temperature giving rise to a continuous structure consisting of three elemental components: a highly crosslinked polymer matrix, a high-volume fraction of inorganic filler of Sphere TEC technology with reduced interparticle matrix and a coupling agent added to ensure matrix-filler adhesion [1]. Thus, the presence of the gradient sized fillers guarantees the least void percentage as reported previously by Elbishari et al. 2012. [32] On the other hand, the microstructure of the ZI is tailored as a sequence of the acid-base setting reaction. Thus, the included water that primarily exists as a solvent, together with the water delivered by the reaction, may accumulate into ultrafine globules during and after setting and eventually diffuse through the set cement leaving behind pores [33-36].

Moreover, the inclusion of such air voids is likely to be a consequence of the manipulative process of the investigated restorative materials during specimen preparation. CX was supplied as single paste in syringe form. The single paste is directly packed into the Teflon mold without mixing and minimum handling, accordingly no opportunity for air incorporation. This could be also extrapolated from earlier studies, where the incorporation of air during spatulation and insertion of hand-mixed chemically cured materials contributed significantly to higher level of porosity in comparison to the minimum handling of 
Hala A. Bahgat et al; Saudi J Oral Dent Res, Oct 2019; 4(10): 751-759

the single-paste light-activated materials during specimen preparation [37-40].

On the contrary, ZI is supplied as two components in powder liquid version, where manual mixing is required for $30 \mathrm{~s}$ with the inevitable air bubbles incorporation due to the viscous nature of the liquid. This finding agrees with several studies, which showed that the hand mixed version of glass ionomer, when compared to encapsulated type, displayed greater operator variability regarding proportioning of the powder and liquid and mixing which might ultimately end by higher intrinsic porosity, reduced strength and higher failure rate [41 -44].

Another important fact, which could be attributed to the different mechanical behaviour of the investigated nano-restoratives, originates principally from the reinforcing filler system, which resists the stresses on loading rather than their weak matrices [1].

The higher flexural strength of $\mathrm{CX}$ could be explained by the specific features of their filler particles. First, they prevent upon loading any mechanical stress concentration in the composite structure by their spherical shape without any sharp angles or protuberances. Secondly, they allow more balanced denser filler particle distribution by the gradient particle size in the nanohybrid composite structure (Table1) [7-9].

With respect to the filler system in ZI, certain limitations restricted its reputable reinforcing effect. Influential information, regarding the percentage of the incorporated nano-zirconia or the particle size distribution of the different filler particles, was not disclosed by the manufacturer. Therefore, the lower flexural strength of ZI might be referred to the nonuniform and non-homogenous distribution of nanoparticles in glass ionomer powder. Also, the greater surface area of the reduced sized $\mathrm{ZrO}_{2}$ particles compared to the reactive glass may interfere with the acid base setting reaction, creating fewer polyacrylate crosslinks leading to poor interfacial bonding between $\mathrm{ZrO}_{2}$ /glass and the polyacrylate matrix, resulting in an overall decline the mechanical strength. This assumption is in alignment with the findings of other studies, which found by scanning electron microscopy that the cracks propagate around the glass and $\mathrm{ZrO}_{2}$ particles rather than propagate through the particles. This suggested that the interfaces between the $\mathrm{ZrO}_{2} /$ glass particles and the ionomer matrix might represent the weak sites in the cement [45-47].

The second null hypothesis must be also rejected for both evaluated nano-restoratives, each of which showed a significant reduction in flexural strength after thermal cycling, mechanical cycling and mechanical cycling followed by thermal cycling.
In laboratory studies, thermal cycling (TC) is a frequently used aging procedure for matching temperature fluctuations that occur in the oral cavity during eating, drinking, and breathing. The thermal cycling regimen differs significantly among experimental studies regarding number of cycles, the temperature of water baths, dwelling time in each bath and transfer time. The adopted thermal cycling protocol in this experimental study correspond to one -year in vivo clinical service as postulated by several authors $[14,48]$. The observed significant decline in the flexural strength of both nano-restoratives matched the results of several previous investigations [49-51]. This reduction could be attributed to the repetitive contraction expansion stresses resulting from mismatching in the coefficients of both filler and matrix components of each nano-restorative. Additionally, the developing thermal stresses might create fissures in the material that could allow continuous ingress of fluids during immersion in the different water baths. Thus, thermal cycling combines both thermal and hydrolytic degradation by repeated sudden changes in temperature.

Moreover, the degradation by thermocycling was significantly higher in ZI could be related to its possible higher percentage of porosity than that of CX, and according to previous study by Aws et al. 2018 [52] porosity will act as a reservoir for water within the structure of material in which water can be retained and transported through the restorative structure.

Also, mechanical cycling (MC) of materials has also gained increased importance in laboratory studies for simulating oral chewing forces. The current study was conducted following the same protocol proposed by previous studies to achieve a constant occlusal load distributed during chewing [17, 18, 53]. The mechanical cycling, like the thermal cycling, reduced significantly the flexural strength of both nanorestoratives. Although this falloff in their flexural strength is higher than that observed due to thermal cycling, but the difference was insignificant. The reduction can be referred to the possibility of localized build-up of higher stresses around their structural defects such as pre-existing voids introduced during material processing, imperfect interfaces, and residual stresses, thus leading to increased susceptibility to crack initiation and growth under repetitive loading application ending up into catastrophic failure [54].

The use of the mechanical cycling combined with thermo-cycling (MTC) raised significantly the detrimental effect on the flexural strength of both nanorestorative materials. This problem has been also addressed by Drummond \& Babna 2003 who reported that the reduction in the flexural strength of fiber reinforced resin materials due to thermo-mechanical cycling indicated that their use in the oral environment reduced their mechanical performance thus threatening their clinical service [55]. 
Hala A. Bahgat et al; Saudi J Oral Dent Res, Oct 2019; 4(10): 751-759

\section{CONCLUSIONS}

The following points could be concluded: 1). The flexural strength of the nanohybrid composite resin material is higher than the nano-zirconia reinforced glass ionomer. 2) The nanohybrid composite resin material showed better mechanical performance than the nano-zirconia reinforced glass ionomer under the different aging test conditions. 3) The aging condition either thermal cycling or mechanical cycling caused comparable detrimental impact on the flexural strength of both nano-restorative materials. 4) The exposure to the combined effect of aging conditions was the most challenging for both nano-restoratives materials.

Clinical implication: This experimental study could help the clinician to highlight feasible mechanical aspect of the restorative's short- and long-term behaviour.

\section{Data Availability}

The data concerning the findings of this investigation are available at the corresponding author upon request.

\section{Conflict of Interest}

No conflicts of interest regarding the publication of this paper.

\section{Funding Statement}

This research was supported by student research grant SG [2016004] College of Dentistry, Imam Abdulrahman University, Saudi Arabia.

\section{ACKNOWLEDGEMENT}

Research team would like to thank Mr. Lindsey Mateo; Dental technician in Prosthodontics Research Lab at IAU for his guidance and great help.

\section{REFERENCES}

1. Sakaguchi, R.L., Powers, J.M. (2012). Craig's restorative dental materials $13^{\text {th }} \mathrm{ed}$. Elsevier Mosby.

2. Tyas, M. J., \& Burrow, M. F. (2004). Adhesive restorative materials: a review. Australian Dental Journal, 49(3), 112-121.

3. Mount, G. J., Tyas, M. J., Ferracane, J. I., Nicholson, J. W., Berg, J. H., Simonsen, R. J., \& Ngo, H. C. (2009). A revised classification for direct tooth-colored restorative materials. Quintessence International, 40(8).

4. Kaul, R., Aradhya, K., \& Sethi, N. (2012). Direct Restorative Material: A New Era. Smile Dental Journal, 110(433), 1-4.

5. Khurshid, Z., Zafar, M., Qasim, S., Shahab, S., Naseem, M., \& AbuReqaiba, A. (2015). Advances in nanotechnology for restorative dentistry. Materials, 8(2), 717-731.

6. Moszner, N., \& Klapdohr, S. (2004). Nanotechnology for dental composites. International Journal of

Nanotechnology, 1(1-2), 130-156.

7. Hegde, M. N., Hegde, P., Bhandary, S., \& Deepika, K. (2011). An evalution of compressive strength of newer nanocomposite: An in vitro study. Journal of conservative dentistry: JCD, 14(1), 36.

8. Scientific Compendium Ceram.x universal https://www.dentsplysirona.com/content/dam/dents ply/pim/manufacturer/Restorative/Direct_Restorati on/Composites__Flowables/Universal_Composites /ceramxuniversal

9. Product news. Superior composite technology. Dentsply Brit Dent J 2016; 220: 213.

10. Xie, D., Brantley, W. A., Culbertson, B. M., \& Wang, G. (2000). Mechanical properties and microstructures of glass-ionomer cements. Dental Materials, 16(2), 129-138.

11. Moshaverinia, A., Roohpour, N., Chee, W. W., \& Schricker, S. R. (2011). A review of powder modifications in conventional glass-ionomer dental cements. Journal of materials chemistry, 21(5), 1319-1328.

12. Almuhaiza, M. (2016). Glass-ionomer cements in restorative dentistry: a critical appraisal. J Contemp Dent Pract, 17(4), 331-336.

13. Zirconomer Improved - Shofu www.shofu.com.sg/downloads/pdf.

14. Gale, M. S., \& Darvell, B. W. (1999). Thermal cycling procedures for laboratory testing of dental restorations. Journal of dentistry, 27(2), 89-99.

15. Abouelleil, H., Jeannin, C., Sadat, A., \& Grosgogeat, B. (2015). Development of a Chewing Simulator for Testing Dental Materials: A Pilot Study. Current Journal of Applied Science and Technology, 1-8.

16. International Standard ISO 4049. (2009). Dentistry. Polymer-based restorative materials. International Standards Organization. ISO, Geneva, Switzerland $4^{\text {th }}$ edition 2009-

17. Zankuli, M. A., Silikas, N., \& Devlin, H. (2015). The Effect of Cyclic Loading on the Compressive Strength of Core Build-Up Materials. Journal of Prosthodontics, 24(7), 549-552.

18. Paula, A. B., Duque, C., Correr-Sobrinho, L., \& Puppin-Rontani, R. M. (2008). Effect of restorative technique and thermal/mechanical treatment on marginal adaptation and compressive strength of esthetic restorations. Operative dentistry, 33(4), 434-440.

19. IBM Corporation, NY, USA.

20. SPSS, Inc., an IBM Company.

21. Abdulsamee, N., \& Elkhadem, A. H. (2017). Zirconomer and Zirconomer Improved (White Amalgams): Restorative Materi-als for the Future. Review. EC Dental Science, 15, 134-150.

22. Eltahlah, D., Lynch, C. D., Chadwick, B. L., Blum, I. R., \& Wilson, N. H. (2018). An update on the reasons for placement and replacement of direct restorations. Journal of dentistry, 72, 1-7. 
Hala A. Bahgat et al; Saudi J Oral Dent Res, Oct 2019; 4(10): 751-759

23. Walker, M. P., Haj-Ali, R., Wang, Y., Hunziker, D., \& Williams, K. B. (2006). Influence of environmental conditions on dental composite flexural properties. Dental materials, 22(11), 10021007.

24. Heintze, S. D., \& Zimmerli, B. (2011). Relevance of in vitro tests of adhesive and composite dental materials, a review in 3 parts. Part 1: Approval requirements and standardized testing of composite materials according to ISO specifications. Schweizer Monatsschrift fur Zahnmedizin= Revue mensuelle suisse d'odontostomatologie $=$ Rivista mensile svizzera di odontologia e stomatologia, 121(9), 804-816.

25. International Organization for Standardization. (2007). 9917-1: Dentistry-Water-based cementspart 1: powder/liquid acid based cements.

26. Prosser, H. J., Powis, D. R., \& Wilson, A. D. (1986). Glass-ionomer cements of improved flexural strength. Journal of dental research, 65(2), 146-148.

27. Fleming, G. J., Dowling, A. H., \& Addison, O. (2012). The crushing truth about glass ionomer restoratives: exposing the standard of the standard. Journal of dentistry, 40(3), 181-188.

28. Dowling, A. H., Fleming, G. J., McGinley, E. L., \& Addison, O. (2012). Improving the standard of the standard for glass ionomers: an alternative to the compressive fracture strength test for consideration?. Journal of dentistry, 40(3), 189201.

29. Heintze, S. D., Ilie, N., Hickel, R., Reis, A., Loguercio, A., \& Rousson, V. (2017). Laboratory mechanical parameters of composite resins and their relation to fractures and wear in clinical trials-A systematic review. Dental materials, 33(3), e101-e114.

30. Geirsson, J., Thompson, J. Y., \& Bayne, S. C. (2004). Porosity evaluation and pore size distribution of a novel directly placed ceramic restorative material. Dental Materials, 20(10), 987995.

31. Rodrigues, D. S., Buciumeanu, M., Martinelli, A. E., Nascimento, R. M., Henriques, B., Silva, F. S., \& Souza, J. C. (2015). Mechanical strength and wear of dental glass-ionomer and resin composites affected by porosity and chemical composition. Journal of Bio-and TriboCorrosion, 1(3), 24.

32. Elbishari, H., Silikas, N., \& Satterthwaite, J. (2012). Filler size of resin-composites, percentage of voids and fracture toughness: is there a correlation?. Dental materials journal, 31(4), 523527.

33. Fano, L., Fano, V., Ma, W. Y., Yang, G. W., \& Zhu, F. (2001). Structure of dental glass-ionomer cements by confocal fluorescence microscopy and stereomicroscopy. Biomaterials, 22(17), 23532358 .
34. Bertenshaw, B. W., \& Piddock, V. (1993). Porosity in water-based dental luting cements. Journal of Materials Science: Materials in Medicine,4(4), 415-417.

35. Milutinović-Nikolić, A. D., Medić, V. B., \& Vuković, Z. M. (2007). Porosity of different dental luting cements. Dental Materials, 23(6), 674-678.

36. Benetti, A. R., Jacobsen, J., Lehnhoff, B., Momsen, N. C., Okhrimenko, D. V., Telling, M. T., ... \& Bordallo, H. N. (2015). How mobile are protons in the structure of dental glass ionomer cements?. Scientific reports, 5, 8972.

37. Valcke, C. F., \& Duggan, T. O. D. (1981). The porosity and roughness of four direct filling resins. Journal of oral rehabilitation, 8(6), 507515.

38. Ogden, A. R. (1985). Porosity in composite resins-an Achilles' heel?. Journal of dentistry, 13(4), 331-340.

39. Chadwick, R. G., McCabe, J. F., Walls, A. W. G., \& Storer, R. (1989). The effect of placement technique upon the compressive strength and porosity of a composite resin. Journal of dentistry, 17(5), 230-233.

40. Fano, V., Ortalli, I., \& Pozela, K. (1995). Porosity in composite resins. Biomaterials, 16(17), 12911295.

41. Hatrick, C.D., Eagle, W.S. (2016). Dental materials. Clinical applications for dental assistants and dental hygienists; $3^{\text {rd }}$ ed, pp.87. Saunders, Elsevier Inc, St Louis, Missouri.

42. Mitchell, C. A., \& Douglas, W. H. (1997). Comparison of the porosity of hand-mixed and capsulated glass-ionomer luting cements. Biomaterials, 18(16), 1127-1131.

43. Nomoto, R., Komoriyama, M., McCabe, J. F., \& Hirano, S. (2004). Effect of mixing method on the porosity of encapsulated glass ionomer cement. Dental Materials, 20(10), 972-978.

44. Freitas, M. C. C. D. A., Fagundes, T. C., Modena, K. C. D. S., Cardia, G. S., \& Navarro, M. F. D. L. (2018). Randomized clinical trial of encapsulated and hand-mixed glass-ionomer ART restorations: one-year follow-up. Journal of Applied Oral Science, 26.

45. Gu, Y. W., Yap, A. U. J., Cheang, P., \& Khor, K. A. (2005). Effects of incorporation of $\mathrm{HA} / \mathrm{ZrO} 2$ into glass ionomer cement (GIC). Biomaterials, 26(7), 713-720.

46. Souza, J. C., Silva, J. B., Aladim, A., Carvalho, O., Nascimento, R. M., Silva, F. S., ... \& Henriques, B. (2016). Effect of zirconia and alumina fillers on the microstructure and mechanical strength of dental glass ionomer cements. The open dentistry journal, 10, 58.

47. Najeeb, S., Khurshid, Z., Zafar, M. S., Khan, A. S., Zohaib, S., Martí, J. M. N., ... \& Rehman, I. U. (2016). Modifications in glass ionomer cements: Nano-sized fillers and bioactive 
nanoceramics. International journal of molecular sciences, 17(7), 1134.

48. Morresi, A. L., D'Amario, M., Capogreco, M., Gatto, R., Marzo, G., D'Arcangelo, C., \& Monaco, A. (2014). Thermal cycling for restorative materials: does a standardized protocol exist in laboratory testing? A literature review. Journal of the mechanical behavior of biomedical materials, 29, 295-308.

49. Morresi, A. L., D’Amario, M., Monaco, A., Rengo, C., Grassi, F. R., \& Capogreco, M. (2015). Effects of critical thermal cycling on the flexural strength of resin composites. Journal of oral science, 57(2), 137-143.

50. Pala, K., Tekçe, N., Tuncer, S., Demirci, M., Öznurhan, F., \& Serim, M. (2017). Flexural strength and microhardness of anterior composites after accelerated aging. Journal of clinical and experimental dentistry, 9(3), e424.
51. Hahnel, S., Henrich, A., Bürgers, R., Handel, G., \& Rosentritt, M. (2010). Investigation of mechanical properties of modern dental composites after artificial aging for one year. Operative Dentistry, 35(4), 412-419.

52. Al-Khadim Aws, H., Abdullah, H., \& Al-Ani Sarah, T. Effect of Thermocycling on the Compressive Strength of Selected Luting Cements.

53. Khamverdi, Z., Sadeghi, Y., Omidipoor, T., Nasr, F., \& Kasraei, S. (2012). Microleakage of Class V Compomer and Light-cured Glass-ionomer Restorations under Load Cycling: An in Vitro Investigation. Avicenna Journal of Dental Research, 4(2), 53-59.

54. Drummond, J. L. (2008). Degradation, fatigue, and failure of resin dental composite materials. Journal of dental research, 87(8), 710-719.

55. Drummond, J. L., \& Bapna, M. S. (2003). Static and cyclic loading of fiber-reinforced dental resin. Dental Materials, 19(3), 226-231. 